\title{
Tetranectin Binds to the Kringle 1-4 Form of Angiostatin and Modifies Its Functional Activity
}

\author{
Tirsit Mogues, ${ }^{1}$ Michael Etzerodt, ${ }^{2}$ Crystal Hall, ${ }^{1}$ Georg Engelich, ${ }^{1}$ Jonas H. Graversen, ${ }^{2}$ \\ and Kevan L. Hartshorn ${ }^{1 *}$ \\ ${ }^{1}$ Hematology and Medical Oncology, School of Medicine, Boston University, Boston, MA 02118, USA \\ ${ }^{2}$ Laboratory of Gene Expression, Department of Molecular and Structural Biology, University of Aarhus, 8000 Aarhus, Denmark
}

Received 22 July 2003; revised 4 December 2003; accepted 4 December 2003

\begin{abstract}
Tetranectin is a plasminogen kringle 4 domain-binding protein present in plasma and various tissue locations. Decreased plasma tetranectin or increased tetranectin in stroma of cancers correlates with cancer progression and adverse prognosis. A possible mechanism through which tetranectin could influence cancer progression is by altering activities of plasminogen or the plasminogen fragment, angiostatin. Tetranectin was found to bind to the kringle 1-4 form of angiostatin (AST ${ }^{\mathrm{K}-4}$ ). In addition, tetranectin inhibited binding of plasminogen or $\mathrm{AST}^{\mathrm{K} 1-4}$ to extracellular matrix (ECM) deposited by endothelial cells. Finally, tetranectin partially counteracted the ability of $\mathrm{AST}^{\mathrm{K} 1-4}$ to inhibit proliferation of endothelial cells. This latter effect of tetranectin was specific for AST ${ }^{\mathrm{K} 1-4}$ since it did not counteract the antiproliferative activities of the kringle 1-3 form of angiostatin (AST ${ }^{\mathrm{Kl}-3}$ ) or endostatin. These findings suggest that tetranectin may modulate angiogenesis through interactions with AST.
\end{abstract}

\section{INTRODUCTION}

Tetranectin (TN) plays a role in skeletal formation during development since targeted deletion of the protein results in spinal deformity [1]. The function(s) of tetranectin in postnatal life have not been elucidated although there is evidence for roles in tissue remodeling, coagulation, and cancer. Tetranectin was originally isolated as a plasminogen-binding protein that can enhance plasminogen activation in the presence of tissue plasminogen activator [2]. Tetranectin binds to plasminogen through a calcium-sensitive interaction of its C-terminal domain with kringle 4 domain of plasminogen [3, 4]. Tetranectin also has a distinct binding site in its $\mathrm{N}$-terminus that mediates binding to complex sulfated carbohydrates (eg, heparin) [5]. The N-terminus of tetranectin could, therefore, mediate binding to extracellular matrix components.

Plasma levels of tetranectin are approximately $100 \mathrm{nM}$ in healthly adults [6]. However, these levels decline in patients with cancer and rheumatoid arthritis $[6,7,8]$. Tetranectin is also found in a mobilizable set of granules in neutrophils [9], in monocytes [10] and platelets [7], and in various tissue locations like cartilage and the extracellular matrix (ECM) of developing or regenerating muscle $[11,12,13]$. Tetranectin is implicated in the pathogenesis of cancer since decreased plasma levels of tetranectin correlate with cancer progression $[6,14]$. In the case of ovarian cancer, decreased plasma levels of tetranectin were a stronger predictor of adverse prognosis than cancer stage [15]. Furthermore, tetranectin is present in the stroma of various cancers (eg, breast, ovary, colon), whereas it is not present in normal tissue from which the cancers arose $[16,17]$. Positive staining for tetranectin in cancer stroma has also been strongly correlated with cancer progression [15].

The mechanisms through which tetranectin may participate in cancer progression have not been elucidated. Tetranectin colocalizes with plasminogen in the invasive front of melanoma lesions [18], although how tetranectin affects binding or local activation of plasminogen in cancer stroma has not been determined. This paper explores the hypothesis that tetranectin may interact with angiostatin. Angiostatin is formed in cancer tissues by proteolytic degradation of plasminogen. The predominant form of angiostatin produced in cancer tissues is $\mathrm{AST}^{\mathrm{Kl} 1-4}$ $[19,20,21] . \mathrm{AST}^{\mathrm{K} 1-4}$ inhibits cancer progression and metastasis by inhibiting cancer-related angiogenesis. We demonstrate that tetranectin binds to $\mathrm{AST}^{\mathrm{K} 1-4}$ and reduces its ability to bind to ECM of endothelial cells or to inhibit endothelial cell growth.

\section{METHODS}

\section{Reagents}

Human plasminogen and an antibody directed against K1-3 domain of plasminogen were purchased from 
Enzyme Research Labs (South Bend, Ind). Rabbit antihuman tetranectin (with or without horseradish peroxidase attached) was obtained from DAKO Corp (Carpinteria, Calif).

\section{Recombinant angiostatins and endostatin}

Recombinant human angiostatins containing kringle domains 1-3 and 1-4 (AST ${ }^{\mathrm{K} 1-3}$ and $\mathrm{AST}^{\mathrm{K} 1-4}$ ), and recombinant human endostatin were graciously provided by Drs Nicolas MacDonald and Kim Lee Sim (EntreMed, Inc, Rockville, Md). AST ${ }^{\mathrm{K} 1-4}$ was produced in Chinese hamster ovary cells and purified as described in [22]. Endostatin and AST $^{\mathrm{K} 1-3}$ were produced in Pichia pastoris $[23,24]$. Native $\mathrm{AST}^{\mathrm{K} 1-4}$ derived from human plasma was purchased from Angiogenesis Research Industries (Chicago, Ill). The recombinant and native angiostatins had similar endothelial cell growth inhibitory properties (data not shown). The native preparation was used in the endothelial growth inhibition assays (see below).

\section{Enzyme-linked immunoabsorbent assay (ELISA) for binding of angiostatin or plasminogen to tetranectin}

Binding of angiostatin or plasminogen to tetranectin was assessed by coating plates initially with wild type or mutant forms of tetranectin. Tetranectin was diluted to a final concentration of $6.8 \mu \mathrm{g} / \mathrm{mL}(100 \mathrm{nM})$ in coating buffer (bicarbonate buffer at $\mathrm{pH}$ 9.6), added to 96-well microtitre plates (Costar, Corning Inc, Corning, NY), and incubated overnight at $4^{\circ} \mathrm{C}$. The wells were washed and then incubated with either plasminogen $(22.5 \mu \mathrm{g} / \mathrm{mL})$ or angiostatin $(50 \mu \mathrm{g} / \mathrm{mL})$ at room temperature for 1 hour. Bound plasminogen or angiostatin was detected by addition of a 1 : 1000 dilution of antibody directed against the kringle 1-3 domain of plasminogen (Enzyme Research Laboratories, South Bend, Ind) for 1 hour at room temperature. Preliminary studies demonstrated that this antibody recognized angiostatin and plasminogen to a similar extent. A secondary antibody (HRP-labeled donkey anti-mouse IgG; Jackson Research Labs, West Grove, Pa) was then added at 1:40000 dilution for 1 hour at room temperature. Binding was detected using a TMB peroxidase EIA substrate kit (BioRad, Hercules, Calif) and $1 \mathrm{~N}$ $\mathrm{H}_{2} \mathrm{SO}_{4}$. OD 450 readings were measured using a Titertek Multiscan reader. In all experiments, background binding of plasminogen and angiostatin was tested by including additional wells coated with $2.5 \%$ BSA only. Note that initial experiments were attempted in which angiostatin or plasminogen was coated onto ELISA plates followed by addition of tetranectin. However, it was found that background binding of tetranectin to BSA-coated plates was too high to reliably assess binding by this method.

\section{Recombinant tetranectins}

Recombinant wild-type human tetranectin was produced in E coli, refolded and purified as described in [10].
Mutant tetranectins were generated by site-directed mutagenesis as described in $[3,4]$.

\section{Assay of binding of plasminogen or angiostatin to ECM of endothelial cells}

ECM was prepared from human umbilical vein endothelial cells (HUVECs) grown for 2 days postconfluence as described in [25]. HUVECs were obtained from Clonetics Products, a division of BioWhittaker (San Diego, Calif) and cultured as outlined in the manufacturer's instructions. The subendothelial matrix was recovered by removing cells with $0.5 \%$ Triton $\mathrm{X}-100$ in PBS ( $\mathrm{pH} 7.4$ ) followed by incubation with $25 \mathrm{mM} \mathrm{NH}_{4} \mathrm{OH}$ to remove cytoskeletal elements, and then washed with PBS supplemented with $0.05 \%$ tween-20. The adherent ECM was incubated with $1 \% \mathrm{BSA}$ in PBS to saturate nonspecific protein binding sites. AST (at $0.5,0.25$, and $0.125 \mu \mathrm{M}$ ) was preincubated with TN (at $100 \mathrm{nM}$ ) for 30 minutes at $37^{\circ} \mathrm{C}$ and then added to designated wells of 96-well plate. Bound AST was detected as described above.

\section{Assay of endothelial cell proliferation}

HUVECs were seeded overnight in minimum essential medium containing $2.5 \%$ fetal bovine serum (FBS) in a 96 -well plate $(5000$ cells/well $)$ at $37^{\circ} \mathrm{C}$. The following day, fresh medium supplemented with basic fibroblast growth factor (bFGF; $10 \mathrm{ng} / \mathrm{mL}$ ) was added. In addition, tetranectin, angiostatin, or endostatin or combinations of these proteins were added to triplicate wells. The cells were incubated for 72 hours by replenishing fresh medium and test substances (bFGF, angiostatin, endostatin, tetranectin) as indicated at 24 hours and 48 hours. Cells were then harvested at 72 hours and counted by hemocytometer.

\section{RESULTS}

\section{Plasminogen and angiostatin bind to tetranectin}

As expected, plasminogen bound to recombinant wild-type tetranectin (Figure 1). Since the form of angiostatin composed of kringle domains 1-4 of plasminogen $\left(\mathrm{AST}^{\mathrm{K} 1-4}\right)$ contains the kringle 4 , we tested its binding to tetranectin in parallel. AST ${ }^{\mathrm{K} 1-4}$ also bound significantly to tetranectin (Figure 1). The mechanism of binding of tetranectin to plasminogen has been determined through the use of tetranectin mutants [3]. Binding is calcium-sensitive (ie, reduced by increasing concentrations of calcium) and is mediated by Cterminal domain of tetranectin. A mutant form of tetranectin in which lysine 148 was replaced with alanine $\left(\mathrm{TN}^{\mathrm{K} 148 \mathrm{~A}}\right)$ binds to plasminogen markedly less than wild type tetranectin [4]. In contrast, substitution of threonine 149 with tyrosine $\left(\mathrm{TN}^{\mathrm{T} 149 \mathrm{Y}}\right)$ resulted in increased binding to kringle 4 [4]. Plasminogen and AST K1-4 bound significantly less to the $\mathrm{TN}^{\mathrm{K} 148 \mathrm{~A}}$ and significantly more to $\mathrm{TN}^{\mathrm{T} 149 \mathrm{Y}}$ than to wild type $\mathrm{TN}$ (Table 1 and Figure 1). 


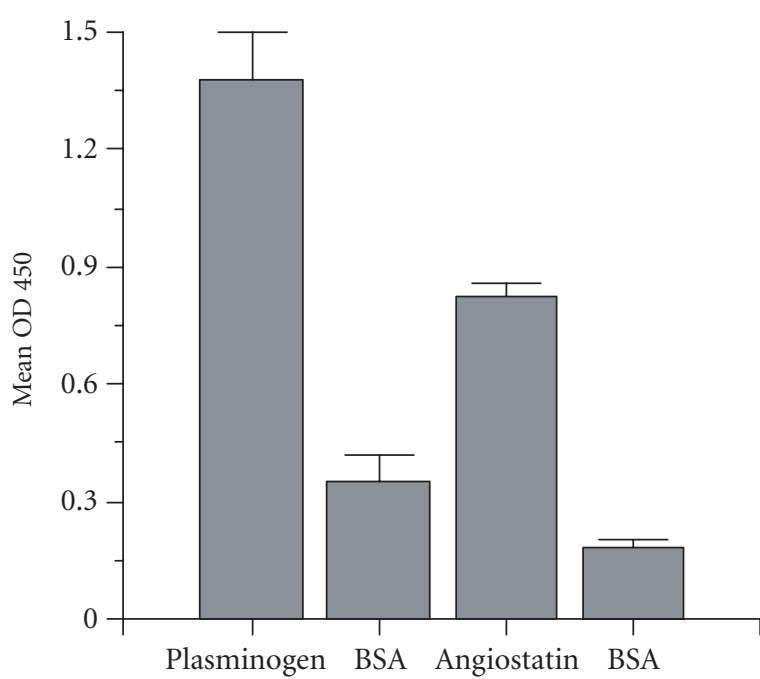

FIGURE 1. Binding of plasminogen or $\mathrm{AST}^{\mathrm{K} 1-4}$ to tetranectin. ELISA plates were coated with recombinant wild-type human tetranectin $(100 \mathrm{nM})$ or BSA, and then treated with plasminogen $(22.5 \mu \mathrm{g} / \mathrm{mL})$ and $\mathrm{AST}^{\mathrm{K} 1-4}(50 \mu \mathrm{g} / \mathrm{mL})$. Results shown are mean \pm SEM of 5 experiments (each experiment done in triplicate). Binding of plasminogen and $\mathrm{AST}^{\mathrm{K} 1-4}$ to tetranectin was significantly greater than binding to BSA-coated plates $(P<.01)$. Binding of plasminogen to TN was significantly greater than binding of $\mathrm{AST}^{\mathrm{K} 1-4}(P<.05)$.

As shown in Figure 1, AST ${ }^{\mathrm{K} 1-4}$ bound to wild-type $\mathrm{TN}$ significantly less than plasminogen. However, binding of $\mathrm{AST}^{\mathrm{K} 1-4}$ to the $\mathrm{TN}^{\mathrm{T} 149 \mathrm{Y}}$ form was equivalent to binding of plasminogen. Increased plasminogen and angiostatin binding of $\mathrm{TN}^{\mathrm{T} 149 \mathrm{Y}}$ could result from the greater affinity of this mutant for kringle 4 . $\mathrm{TN}^{\mathrm{T} 149 \mathrm{Y}}$ is also distinguished from wild-type tetranectin in that it binds to the kringle 2 domain of plasminogen [4], which could be involved in binding to $\mathrm{AST}^{\mathrm{K} 1-4}$. This is likely to be the case since $\mathrm{AST}^{\mathrm{K} 1-3}$ showed significant binding to $\mathrm{TN}^{\mathrm{Y} 149 \mathrm{~A} \text {, }}$ whereas binding of wild-type TN to $\mathrm{AST}^{\mathrm{K} 1-3}$ was not significantly greater than background binding to BSA (data not shown). Nonetheless, binding of AST ${ }^{\mathrm{K} 1-3}$ to $\mathrm{TN}^{\mathrm{T} 149 \mathrm{Y}}$ was markedly less than that of $\mathrm{AST}^{\mathrm{K} 1-4}$ or plasminogen, indicating that increased affinity of $\mathrm{TN}^{\mathrm{T} 149 \mathrm{Y}}$ for kringle 4 accounts for most of the increased binding of this mutant to $\mathrm{AST}^{\mathrm{K} 1-4}$.

\section{Angiostatin (AST ${ }^{K 1-4}$ ) binds to ECM of endothelial cells and tetranectin inhibits this binding}

Our next goal was to determine if tetranectin alters functional activities of angiostatin. Plasminogen binds to ECM of endothelial cells $[25,26]$. We wanted to determine if angiostatin also binds to ECM of endothelial cells and to determine the effect of tetranectin on this binding. ECM of HUVECs was prepared as described in [25]. As shown in Figure 2, plasminogen did bind to this matrix and this binding was significantly inhibited by pre-incubation of

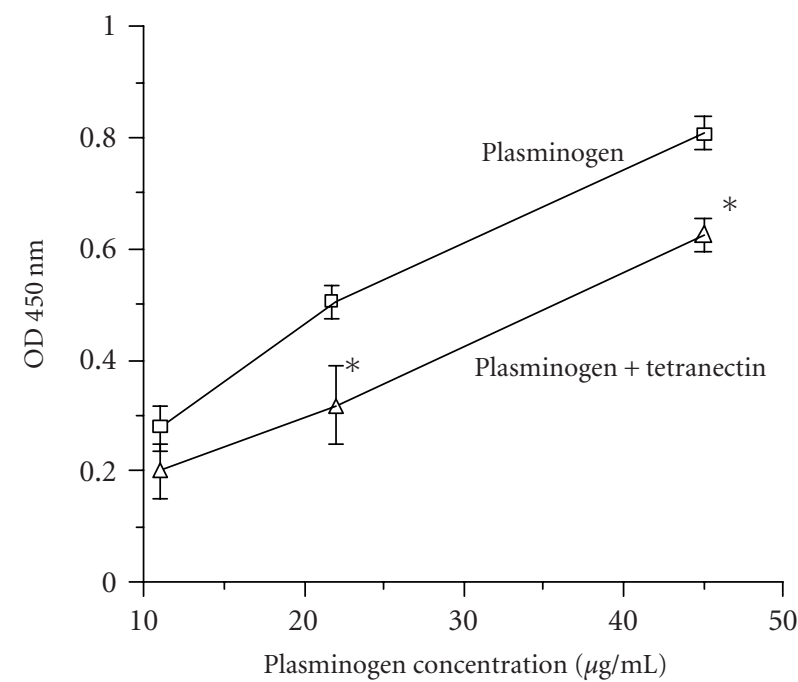

FIGURE 2. Tetranectin reduces binding of plasminogen to ECM deposited by endothelial cells. ECM of endothelial cells was produced as described in "methods," and binding of plasminogen was measured using ELISA. The effect of tetranectin (wild type) on binding of plasminogen was assessed by preincubation of plasminogen with tetranectin $(100 \mathrm{nM})$ for 30 minutes at $37^{\circ} \mathrm{C}$, followed by addition of these samples to wells coated with ECM. Results shown are mean \pm SEM of 4 experiments (each experiment done in triplicate). Binding of plasminogen at 22.5 or $45 \mu \mathrm{g} / \mathrm{mL}$ was significantly reduced by tetranectin $(P<.05$; indicated by ${ }^{*}$ ).

TABLE 1. Binding of plasminogen and angiostatin, containing kringles 1-4 or kringles 1-3 (AST ${ }^{\mathrm{K} 1-4}, \mathrm{AST}^{\mathrm{K} 1-3}$ ), to mutant tetranectins. Binding of plasminogen, angiostatin K1-4 $\left(\mathrm{AST}^{\mathrm{K} 1-4}\right)$, or angiostatin K1-3 (AST ${ }^{\mathrm{K} 1-3}$ ) to TN mutants was assessed by ELISA as in Figure 1. Results shown are mean \pm SEM of 6 specific binding determinations. Binding of plasminogen or AST to BSA was subtracted from results shown.

\begin{tabular}{lll}
\hline Protein added & $\mathrm{TN}^{\mathrm{K} 148 \mathrm{~A}}$ & $\mathrm{TN}^{\mathrm{T} 149 \mathrm{Y}}$ \\
\hline Plasminogen & $0.02 \pm 0.006$ & $1.73 \pm 0.14$ \\
AST $^{\mathrm{K} 1-4}$ & $0.06 \pm 0.02$ & $1.83 \pm 0.21$ \\
AST $^{\mathrm{K} 1-3}$ & $0.02 \pm 0.006$ & $0.43 \pm 0.05$ \\
\hline
\end{tabular}

plasminogen with a physiological concentration $(100 \mathrm{nM})$ of wild-type tetranectin. As shown in Figure 3, AST ${ }^{\mathrm{K} 1-4}$ also bound to the ECM and binding was again significantly reduced by tetranectin.

\section{Tetranectin modulates the ability of angiostatin to inhibit endothelial cell proliferation}

$\mathrm{AST}^{\mathrm{K} 1-4}$ significantly inhibited the bFGF-stimulated growth of HUVECs as expected (Figure 4). Tetranectin alone did not significantly alter proliferation in the presence (Figure 4) or absence (data not shown) of bFGF. However, when HUVECs were treated with both tetranectin and $\mathrm{AST}^{\mathrm{K} 1-4}$, proliferation was significantly greater than that with $\mathrm{AST}^{\mathrm{K} 1-4}$ alone. Note that tetranectin did not completely reverse the antiproliferative action of 


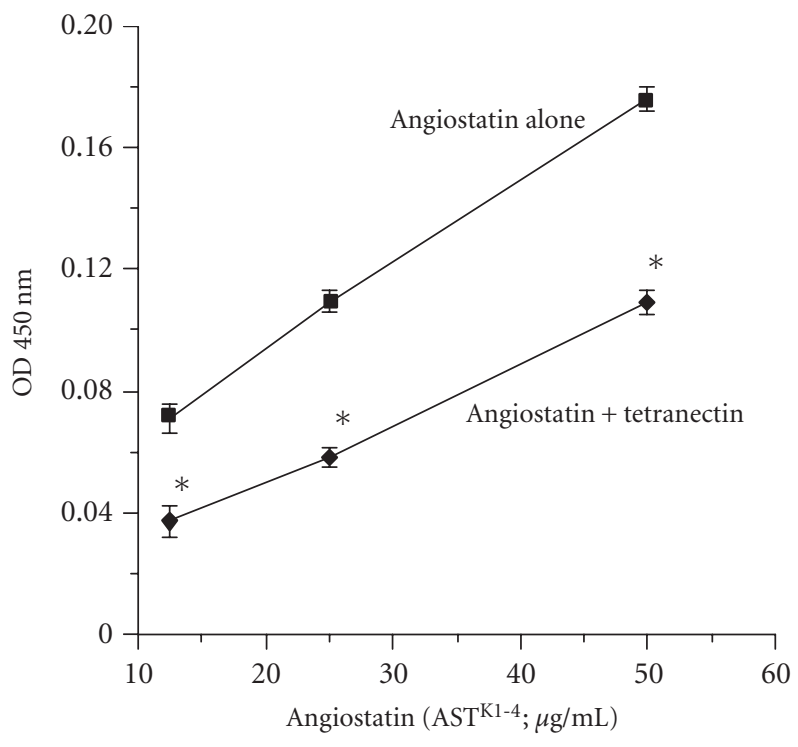

Figure 3. Tetranectin reduces binding of angiostatin to ECM. Binding of angiostatin (AST ${ }^{\mathrm{K} 1-4}$ ) to ECM of endothelial cells was measured as in Figure 2. At all concentrations tested, binding of $\mathrm{AST}^{\mathrm{K} 1-4}$ was significantly reduced by tetranectin $(P<.05$; indicated by $\left.{ }^{*}\right)$. Results shown are mean \pm SEM of 4 experiments (each experiment done in triplicate).

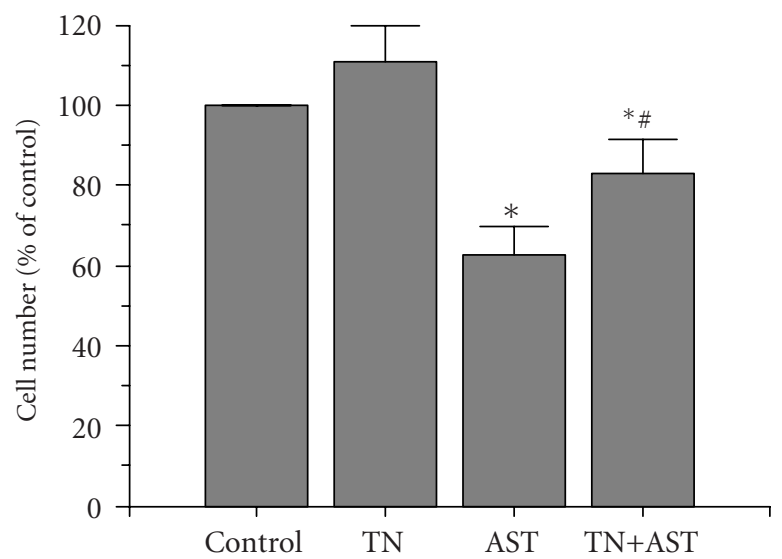

FIgURE 4. Tetranectin counteracts angiostatin-induced inhibition of proliferation of endothelial cells. HUVECs were seeded overnight in 96-well plates (5000 cells/well). The following day, fresh medium supplemented with basic fibroblast growth factor (bFGF; $10 \mathrm{ng} / \mathrm{mL}$ ) was added. Where indicated, tetranectin (TN; $100 \mathrm{nM})$ and/or AST ${ }^{\mathrm{K} 1-4}(200 \mathrm{nM})$ were added to triplicate wells. Cell numbers were counted after 72 hours. AST ${ }^{\mathrm{K} 1-4}$ significantly reduced the number of cells obtained $\left(P<.008\right.$; indicated by $\left.{ }^{*}\right)$. There were, however, significantly more cells in cultures treated with the combination of tetranectin and $\mathrm{AST}^{\mathrm{K} 1-4}$ than in those treated with $\mathrm{AST}^{\mathrm{K} 1-4}$ alone $(P<.039$; indicated by \#). Note that cultures treated with AST and tetranectin still have less cells than control cultures $(P<.05)$.

$\mathrm{AST}^{\mathrm{K} 1-4}$ since there were still significantly fewer cells in cultures treated with the combination of tetranectin and $\mathrm{AST}^{\mathrm{K} 1-4}$ than in control cultures.
TABLE 2. Effect of tetranectin on endothelial cell proliferation in presence of control buffer, $\mathrm{AST}^{\mathrm{K} 1-3}$ or endostatin. Endothelial cell cultures were incubated for 72 hours in presence of the indicated concentrations of recombinant wild-type tetranectin, $\mathrm{AST}^{\mathrm{K} 1-3}$, or endostatin alone or combinations of $\mathrm{AST}^{\mathrm{K} 1-3}$ or endostatin with tetranectin (final concentration $150 \mathrm{nM}$ ). Results represent mean \pm SD number of cells $/ \mathrm{mL}(\times 1000)$ in $4-6$ experiments (each done in triplicate). All concentrations of AST ${ }^{\mathrm{K} 1-3}$ or endostatin significantly decreased endothelial cells numbers $(P<.05)$ in presence or absence of tetranectin. Tetranectin alone significantly $(P<.01)$ increased the number of endothelial cells compared with control buffer alone although it did not alter the effects of any concentration of $\mathrm{AST}^{\mathrm{K} 1-3}$ or endostatin.

\begin{tabular}{lcc}
\hline Inhibitor added & Control & Tetranectin $150 \mathrm{nM}$ \\
\hline Control & $43.4 \pm 1.4$ & $51 \pm 2.9^{* *}$ \\
$\mathrm{AST}^{\mathrm{K} 1-3} 10 \mathrm{nM}$ & $40.5 \pm 1.9$ & $37.6 \pm 5.7$ \\
$\mathrm{AST}^{\mathrm{K} 1-3} 50 \mathrm{nM}$ & $33.2 \pm 2.2$ & $34.1 \pm 4$ \\
$\mathrm{AST}^{\mathrm{K} 1-3} 1 \mu \mathrm{M}$ & $32.3 \pm 1.6$ & $27.7 \pm 1.6$ \\
Endostatin $125 \mathrm{nM}$ & $32.3 \pm 2$ & $30.3 \pm 2$ \\
Endostatin $250 \mathrm{nM}$ & $27.2 \pm 1.9$ & $23.1 \pm 7$ \\
Endostatin $500 \mathrm{nM}$ & $25.1 \pm 3.5$ & $22 \pm 3.9$ \\
\hline
\end{tabular}

In the experiments shown in Figure 4, there was a trend (not statistically significant) toward increased proliferation of endothelial cells in response to tetranectin alone. It was possible, therefore, that the ability of tetranectin to counteract the antiproliferative activity of $\mathrm{AST}^{\mathrm{K} 1-4}$ resulted from independent effects of tetranectin on endothelial cell proliferation, rather than from its interaction with $\mathrm{AST}^{\mathrm{K} 1-4}$. To study this further, we tested the activity of additional concentrations of tetranectin alone, or tetranectin in combination with endostatin or $\mathrm{AST}^{\mathrm{K} 1-3}$ (Table 2). In these experiments, $150 \mathrm{nM}$ concentration of tetranectin alone modestly but significantly increased endothelial cell proliferation. However, a further increase of the concentration of tetranectin to $375 \mathrm{nM}$ resulted in loss of this enhancing activity (ie, endothelial cell counts in cultures treated with $375 \mathrm{nM}$ tetranectin were $38 \pm 3 \times 10^{3}$ as compared to $43 \pm 1.4$ in control; $n=6 ; P<.06$ ). Both endostatin and $\mathrm{AST}^{\mathrm{K} 1-3}$ inhibited the growth of endothelial cells as expected (Table 2). However, tetranectin $(150 \mathrm{nM})$ did not lessen the antiproliferative effect of either $\mathrm{AST}^{\mathrm{K} 1-3}$ or endostatin. These results suggest that the ability of tetranectin to counteract the antiproliferative activity of $\mathrm{AST}^{\mathrm{K} 1-4}$ is not the result of an independent effect of tetranectin on the endothelial cells.

\section{DISCUSSION}

The important novel findings of this paper are that tetranectin binds to $\mathrm{AST}^{\mathrm{K} 1-4}$, inhibits binding of plasminogen and $\mathrm{AST}^{\mathrm{K} 1-4}$ to ECM of endothelial cells, and partially counteracts the effects of $\mathrm{AST}^{\mathrm{K} 1-4}$ on endothelial cell proliferation. The mechanism of binding of AST ${ }^{\mathrm{K} 1-4}$ to tetranectin is similar to that of plasminogen based on 
studies using mutant forms of tetranectin with enhanced or reduced ability to bind plasminogen (Table 1). These results also indicate that interactions of $\mathrm{AST}^{\mathrm{K} 1-4}$ with tetranectin could be modulated through introduction of discrete modifications of tetranectin's binding site for plasminogen.

It is of note that although tetranectin bound significantly to $\mathrm{AST}^{\mathrm{K} 1-4}$, binding to $\mathrm{AST}^{\mathrm{K} 1-4}$ was significantly less than binding to plasminogen. This finding was unexpected since $\mathrm{AST}^{\mathrm{K} 1-4}$ contains the principal binding site for tetranectin (ie, kringle 4). It may be that the conformation of kringle 4 in $\mathrm{AST}^{\mathrm{K} 1-4}$ differs sufficiently from its conformation in plasminogen to affect binding of tetranectin. This binding difference may be significant in some physiological situations. However, the other results presented in this paper indicate strongly that binding of tetranectin to AST $\mathrm{K}^{\mathrm{K}-4}$ is sufficient to affect other activities of $\mathrm{AST}^{\mathrm{K} 1-4}$.

We demonstrate that $\mathrm{AST}^{\mathrm{K} 1-4}$, like plasminogen, binds to the ECM of endothelial cells. This finding is novel and of interest since it could relate to localization of angiostatin in vivo. Of more relevance to the aims of this paper, we also found that tetranectin significantly reduced binding of AST ${ }^{\mathrm{K} 1-4}$ to ECM of endothelial cells. The ability of tetranectin to inhibit binding of $\mathrm{AST}^{\mathrm{K} 1-4}$ to ECM suggests that it could promote angiogenesis in vivo. We therefore tested whether tetranectin affects the antiangiogenic activity of $\mathrm{AST}^{\mathrm{K} 1-4}$. Physiological concentrations of wildtype tetranectin significantly counteracted the effect of $\mathrm{AST}^{\mathrm{K} 1-4}$ on endothelial cell proliferation. Tetranectin did not have a similar interaction with $\mathrm{AST}^{\mathrm{K} 1-3}$ or endostatin (Table 2), indicating that its ability to counteract the antiangiogenic effects of AST ${ }^{\mathrm{K} 1-4}$ is dependent on binding to the kringle 4 domain and not to some other direct interaction with endothelial cells. Tetranectin alone had a variably enhancing effect on endothelial cell growth at some concentrations. However, this effect was not dose-related and is unlikely to account for the ability of tetranectin to counteract antiproliferative effects of $\mathrm{AST}^{\mathrm{K} 1-4}$ based upon results shown in Table 2.

As noted, extensive data derived from the study of clinical samples suggests that increased tetranectin in the stroma of cancer tissues is associated with an adverse prognosis in various cancers. Our findings suggest that tetranectin may promote tumor progression by favoring angiogenesis. Cancer-associated angiogenesis has been quantitated by enumeration of the density of microvessels in tumor stroma. Increased microvessel density is associated with adverse prognosis in many cancers [27]. Future studies could address whether increased microvessel density is associated with stromal tetranectin reactivity. The ability of tetranectin to modify other functional properties of angiostatin should also be examined. One immediate implication of our findings is that $\mathrm{AST}^{\mathrm{K} 1-4}$ and $\mathrm{AST}^{\mathrm{K} 1-3}$ may have different activities in vivo based on differential binding to tetranectin. This might account for the increased elimination half-life of $\mathrm{AST}^{\mathrm{K} 1-4}$ compared with $\mathrm{AST}^{\mathrm{K} 1-3}$ in vivo, or the fact that a similar inhibition of cancer metastases was obtained with lower effective in vivo exposure to $\mathrm{AST}^{\mathrm{K} 1-3}$ than $\mathrm{AST}^{\mathrm{K} 1-4}$ [22].

Angiostatin may inhibit angiogenesis in inflammatory states [28] or after vascular injury [29]. Recent studies demonstrate that biologically active angiostatin is produced by neutrophils [30], and that angiostatin inhibits neutrophil migration and inflammation-induced angiogenesis [31]. Of interest, prior studies demonstrated that tetranectin is contained in a subset of neutrophils, from which it can be released after cell stimulation with various agonists [9]. Hence, interactions of tetranectin and plasminogen or angiostatin may also be involved in inflammatory processes. Whereas angiostatin produced in cancer tissues appears most often to be $\operatorname{AST}^{\mathrm{K} 1-4}[19,21]$, neutrophils produce AST ${ }^{\mathrm{K} 1-3}$ [30]. Therefore, the participation of tetranectin in angiogenesis may vary in different physiological or pathological states depending on which form of angiostatin is produced.

In summary, we demonstrate that tetranectin binds to the form of angiostatin commonly produced in cancer tissues, characterize the mechanism of binding using mutant forms of tetranectin, and show that tetranectin inhibits important functional properties of angiostatin. These findings provide insight into the mechanisms through which tetranectin participates in cancer progression. Furthermore, these findings have implications for therapeutic use of different forms of angiostatin.

\section{ACKNOWLEDGMENT}

This work was supported by NIH Grant HL69031 (KLH).

\section{REFERENCES}

[1] Iba K, Durkin ME, Johnsen L, et al. Mice with a targeted deletion of the tetranectin gene exhibit a spinal deformity. Mol Cell Biol. 2001;21(22):7817-7825.

[2] Clemmensen I, Petersen LC, Kluft C. Purification and characterization of a novel, oligomeric, plasminogen kringle 4 binding protein from human plasma: tetranectin. Eur J Biochem. 1986;156(2): 327-333.

[3] Graversen JH, Lorentsen RH, Jacobsen C, et al. The plasminogen binding site of the C-type lectin tetranectin is located in the carbohydrate recognition domain, and binding is sensitive to both calcium and lysine. J Biol Chem. 1998;273(44):2924129246.

[4] Graversen JH, Jacobsen C, Sigurskjold BW, et al. Mutational analysis of affinity and selectivity of kringletetranectin interaction. Grafting novel kringle affinity onto the tetranectin lectin scaffold. J Biol Chem. 2000;275(48):37390-37396.

[5] Lorentsen RH, Graversen JH, Caterer NR, Thogersen HC, Etzerodt M. The heparin-binding site in 
tetranectin is located in the $\mathrm{N}$-terminal region and binding does not involve the carbohydrate recognition domain. Biochem J. 2000;347 (pt 1):83-87.

[6] Jensen BA, Clemmensen I. Plasma tetranectin is reduced in cancer and related to metastasia. Cancer. 1988;62(5):869-872.

[7] Christensen L. The distribution of fibronectin, laminin and tetranectin in human breast cancer with special attention to the extracellular matrix. APMIS Suppl. 1992;26:1-39.

[8] Kamper EF, Kopeikina LT, Koutsoukos V, Stavridis J. Plasma tetranectin levels and disease activity in patients with rheumatoid arthritis. J Rheumatol. 1997;24(2):262-268.

[9] Borregaard N, Christensen L, Bejerrum OW, Birgens HS, Clemmensen I. Identification of a highly mobilizable subset of human neutrophil intracellular vesicles that contains tetranectin and latent alkaline phosphatase. J Clin Invest. 1990;85(2):408-416.

[10] Nielsen H, Clemmensen I, Kharazmi A. Tetranectin: a novel secretory protein from human monocytes. Scand J Immunol. 1993;37(1):39-42.

[11] Wewer UM, Ibaraki K, Schjorring P, Durkin ME, Young MF, Albrechtsen R. A potential role for tetranectin in mineralization during osteogenesis. $J$ Cell Biol. 1994;127(6):1767-1775.

[12] Clemmensen I, Lund LR, Christensen L, Andreasen PA. A tetranectin-related protein is produced and deposited in extracellular matrix by human embryonal fibroblasts. Eur J Biochem. 1991;195(3):735741.

[13] Wewer UM, Iba K, Durkin ME, et al. Tetranectin is a novel marker for myogenesis during embryonic development, muscle regeneration, and muscle cell differentiation in vitro. Dev Biol. 1998;200(2):247-259.

[14] Hogdall CK, Christiansen M, Norgaard-Pedersen B, Bentzen SM, Kronborg O, Clemmensen I. Plasma tetranectin and colorectal cancer. Eur J Cancer. 1995;31A(6):888-894.

[15] Hogdall CK, Hogdall EV, Hording U, Clemmensen I, Norgaard-Pedersen B, Toftager-Larsen K. Preoperative plasma tetranectin as a prognostic marker in ovarian cancer patients. Scand J Clin Lab Invest. 1993;53(7):741-674.

[16] Wewer UM, Albrechtsen R. Tetranectin, a plasminogen kringle 4-binding protein. Cloning and gene expression pattern in human colon cancer. Lab Invest. 1992;67(2):253-262.

[17] Christensen L, Clemmensen I. Differences in tetranectin immunoreactivity between benign and malignant breast tissue. Histochemistry. 1991;95(5): 427-433.

[18] De Vries TJ, De Wit PE, Clemmensen I, et al. Tetranectin and plasmin/plasminogen are similarly distributed at the invasive front of cutaneous melanoma lesions. J Pathol. 1996;179(3):260-265.

[19] O’Reilly MS, Holmgren L, Shing Y, et al. Angiostatin: a novel angiogenesis inhibitor that mediates the sup- pression of metastases by a Lewis lung carcinoma. Cell. 1994;79(2):315-328.

[20] Gately S, Twardowski P, Stack MS, et al. The mechanism of cancer-mediated conversion of plasminogen to the angiogenesis inhibitor angiostatin. Proc Natl Acad Sci USA. 1997;94(20):10868-10872.

[21] Richardson M, Gunawan J, Hatton MW, Seidlitz E, Hirte HW, Singh G. Malignant ascites fluid (MAF), including ovarian-cancer-associated MAF, contains angiostatin and other factor(s) which inhibit angiogenesis. Gynecol Oncol. 2002;86(2):279-287.

[22] MacDonald NJ, Murad AC, Fogler WE, Lu Y, Sim BK. The tumor-suppressing activity of angiostatin protein resides within kringles 1 to 3. Biochem Biophys Res Commun. 1999;264(2):469-477.

[23] Sim BK, O'Reilly MS, Liang H, et al. A recombinant human angiostatin protein inhibits experimental primary and metastatic cancer. Cancer Res. 1997;57(7):1329-1334.

[24] Sim BK, Fogler WE, Zhou XH, et al. Zinc liganddisrupted recombinant human Endostatin: potent inhibition of tumor growth, safety and pharmacokinetic profile. Angiogenesis. 1999;3(1):41-51.

[25] Knudsen BS, Silverstein RL, Leung LL, Harpel PC, Nachman RL. Binding of plasminogen to extracellular matrix. J Biol Chem. 1986;261(23):10765-10771.

[26] Stack MS, Gately S, Bafetti LM, Enghild JJ, Soff GA. Angiostatin inhibits endothelial and melanoma cellular invasion by blocking matrix-enhanced plasminogen activation. Biochem J. 1999;340(pt 1):7784.

[27] Hlatky L, Hahnfeldt P, Folkman J. Clinical application of antiangiogenic therapy: microvessel density, what it does and doesn't tell us. J Natl Cancer Inst. 2002;94(12):883-893.

[28] Hamacher J, Lucas R, Lijnen HR, et al. Tumor necrosis factor-alpha and angiostatin are mediators of endothelial cytotoxicity in bronchoalveolar lavages of patients with acute respiratory distress syndrome. Am J Respir Crit Care Med. 2002;166(5):651-656.

[29] Matsunaga T, Weihrauch DW, Moniz MC, Tessmer J, Warltier DC, Chilian WM. Angiostatin inhibits coronary angiogenesis during impaired production of nitric oxide. Circulation. 2002;105(18):21852191.

[30] Scapini P, Nesi L, Morini M, et al. Generation of biologically active angiostatin kringle 1-3 by activated human neutrophils. J Immunol. 2002;168(11):57985804.

[31] Benelli R, Morini M, Carrozzino F, et al. Neutrophils as a key cellular target for angiostatin: implications for regulation of angiogenesis and inflammation. FASEB J. 2002;16(2):267-269.

* Corresponding author.

E-mail: khartsho@bu.edu

Fax: +1 617638 7530; Tel: +1 6176385638 

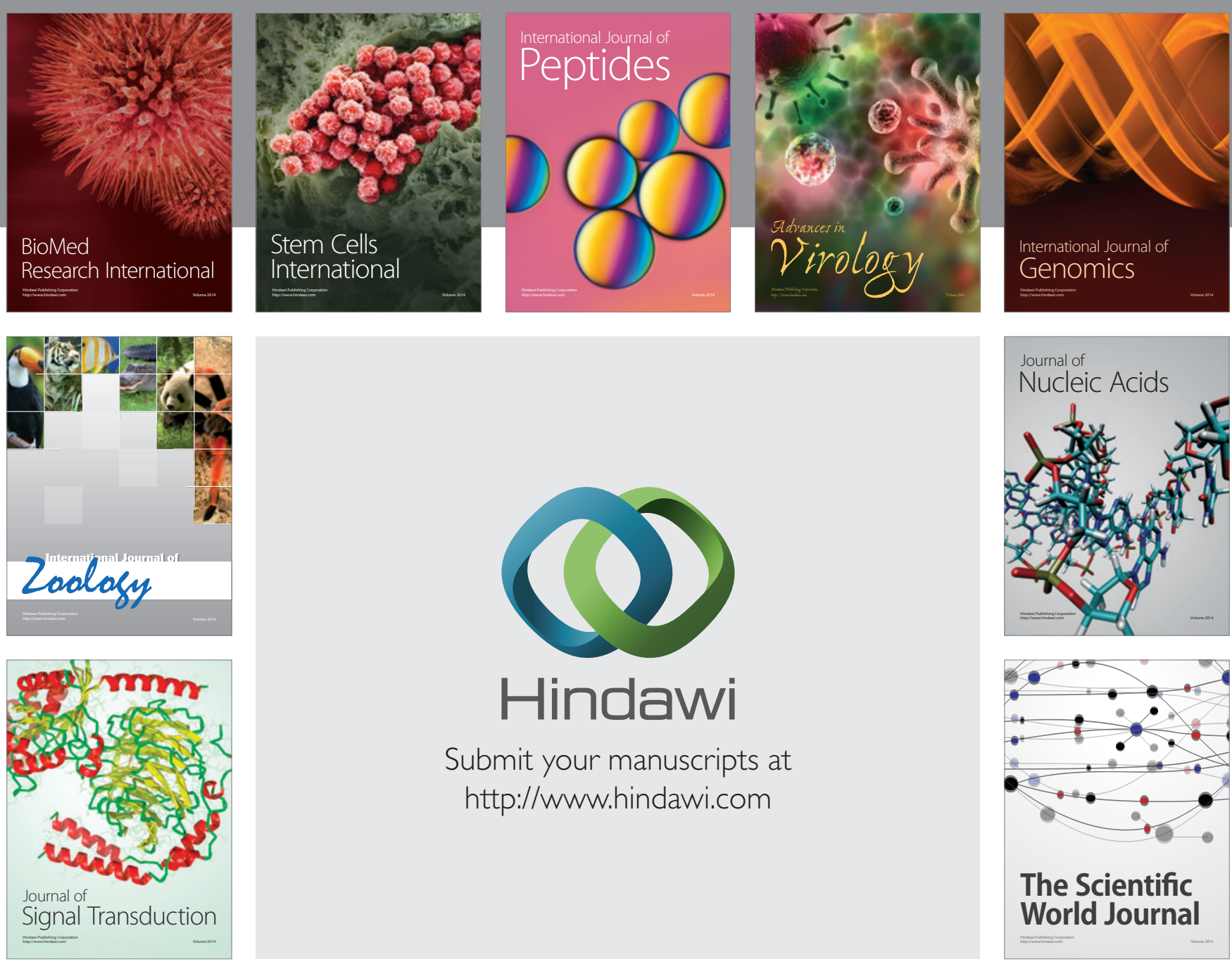

Submit your manuscripts at

http://www.hindawi.com
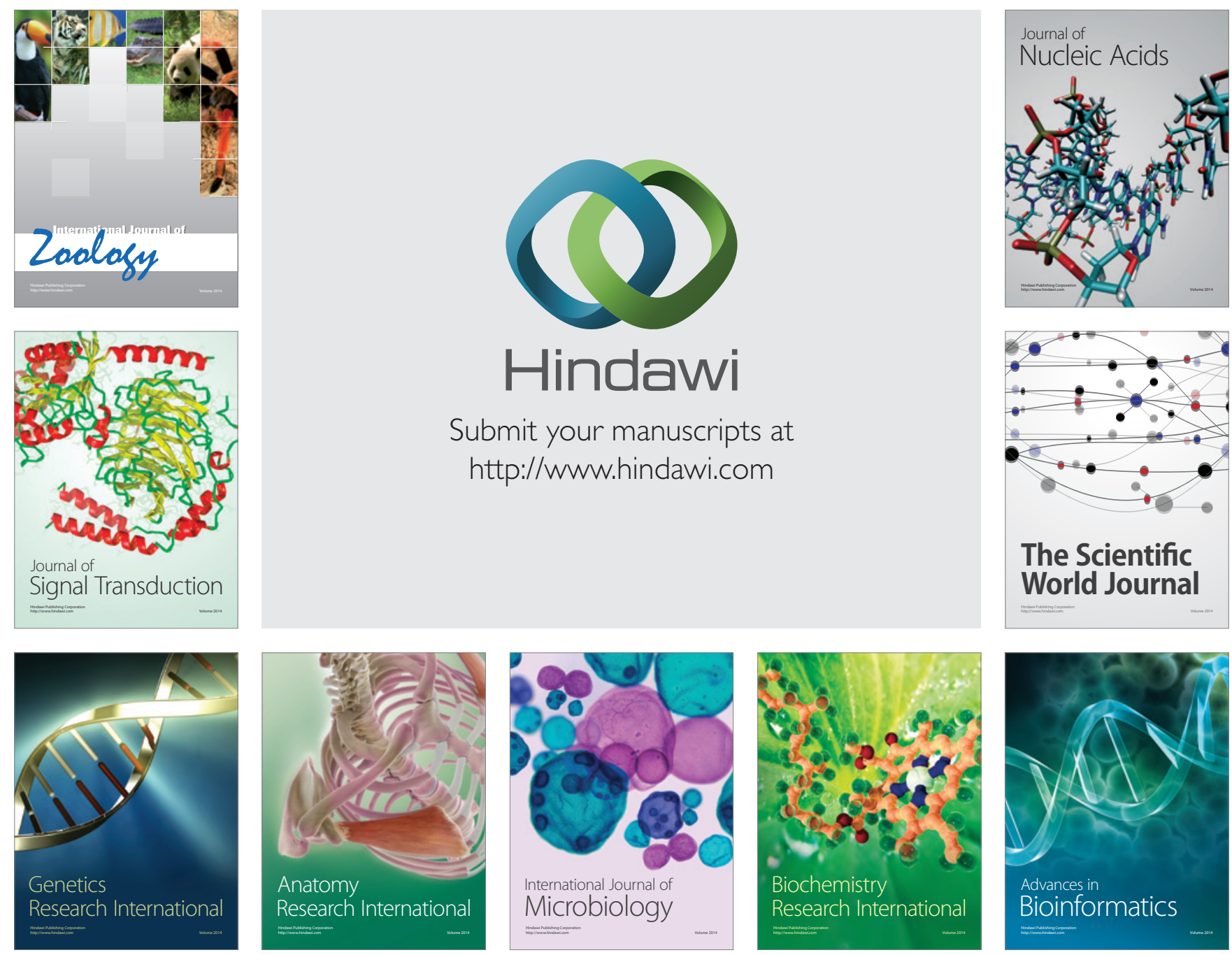

The Scientific World Journal
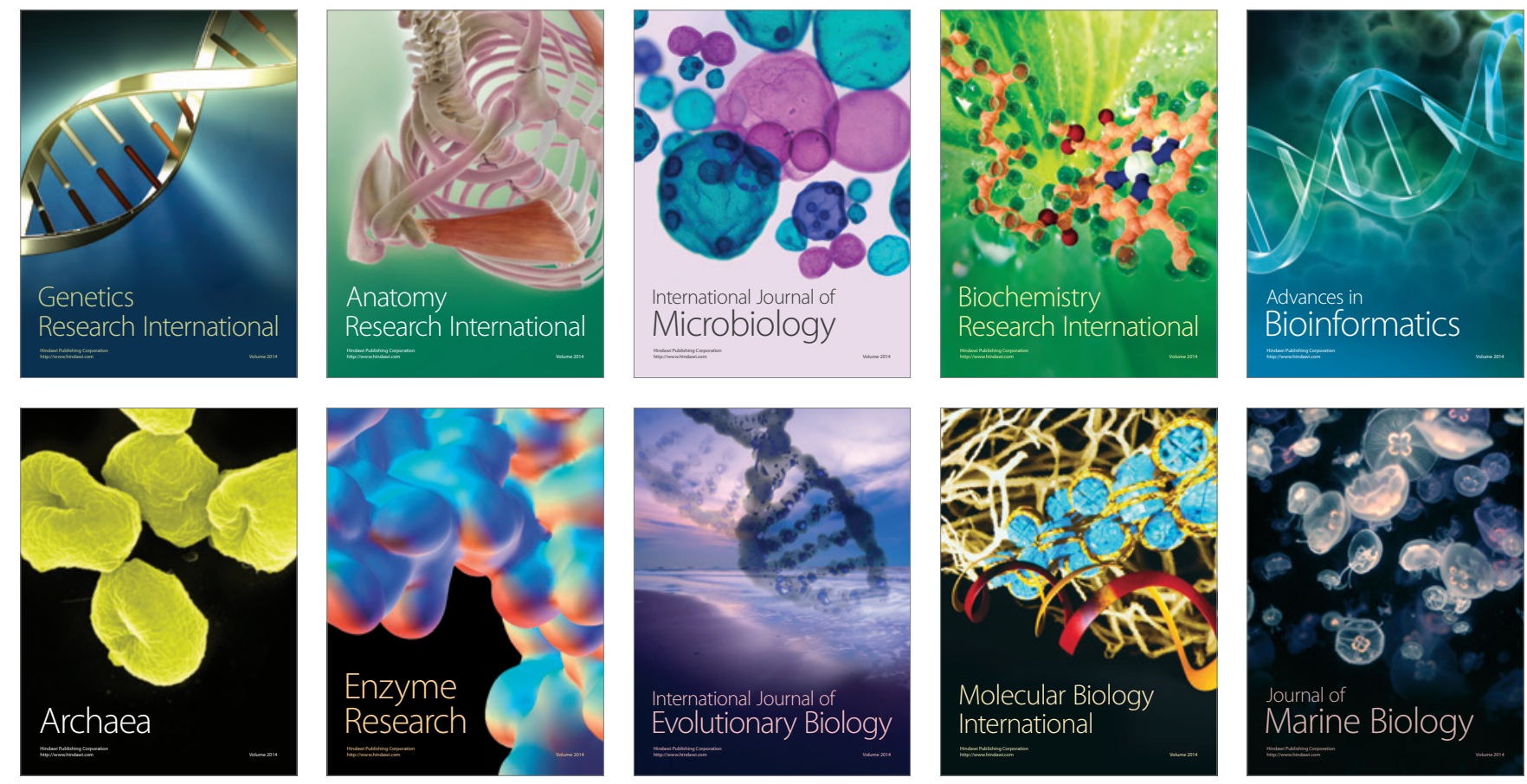